\title{
Quality-improvement strategies for the management of hypertension in chronic kidney disease in primary care: a systematic review
}

\author{
Hugh Gallagher, Simon de Lusignan, Kevin Harris and Christopher Cates
}

\begin{abstract}
Background

Chronic kidney disease (CKD) is a relatively recently recognised condition. People with CKD are much more likely to suffer from cardiovascular events than progress to established renal failure. Controlling systolic blood pressure should slow the progression of disease and reduce mortality and morbidity. However, no systematic review has been conducted to explore the effectiveness of quality-improvement interventions to lower blood pressure in people with CKD.
\end{abstract}

Aim

To assess the effectiveness of quality-improvement interventions to reduce systolic blood pressure in people with CKD in primary care, in order to reduce cardiovascular risk and slow the progression of renal disease.

\section{Method}

Papers were identified from the trial data bases of the Cochrane Effective Practice and Organisation of Care Group (EPOC) and Cochrane renal groups. In a threeround process, at least two investigators read the papers independently. Studies were initially excluded based on their abstracts, if these were not relevant to primary care. Next, full papers were read, and again excluded on relevance. Quantitative and, where this was not possible, qualitative analyses of the findings were performed. Results

The selected studies were usually carried out on high-risk populations including ethnic minorities. The interventions were most often led by nurses or pharmacists. Three randomised trials showed a combined effect of a reduction in systolic blood pressure of $10.50 \mathrm{mmHg}$ (95\% confidence interval $[\mathrm{Cl}]=5.34$ to $18.41 \mathrm{mmHg}$ ). One non-randomised study showed a reduction in systolic blood pressure of $9.30 \mathrm{mmHg}(95 \% \mathrm{Cl}=3.01$ to $15.58 \mathrm{mmHg}$ ).

Conclusion

Quality-improvement interventions can be effective in lowing blood pressure, and potentially in reducing cardiovascular risk and slowing progression in CKD. Trials are needed in low-risk populations to see if the same improvements can be achieved.

\section{Keywords}

Blood pressure; diabetes mellitus; evidence-based medicine; hypertension; kidney failure, chronic; quality assurance, health care.

\section{INTRODUCTION}

Chronic kidney disease (CKD) is a new priority for primary care, and cross-sectional studies show that there is a gap between evidence and practice. ${ }^{1}$ At present, many people are not managed according to current guidance. ${ }^{2}$ People with CKD are at greater risk of cardiovascular morbidity and mortality, which are approximately equal to and additive to the excess rates seen in diabetes. ${ }^{3}$ Only a small minority of people with CKD progress to dialysis dependence. The 2008 UK Renal Registry report indicates a prevalent dialysis population of $0.07 \% .{ }^{4}$ Data from East Kent indicate that over $80 \%$ of people with CKD have a disease that is stable over time..$^{5}$ It has been estimated that the cost of implementation of national guidance could be recouped by delaying the dialysis of one patient per practice of 10000 patients for a single year. ${ }^{6}$

CKD is common, affecting $5-10 \%$ of the population. ${ }^{78}$ It can be diagnosed from a blood test,

H Gallagher, PhD, FRCP, honorary senior lecturer/consultant nephrologist; S de Lusignan, MSc, MD, FBCS CITP, FRCGP, reader in general practice and biomedical informatics, Division of Community Health Sciences; C Cates, MA, FRCGP, senior clinical research fellow St George's - University of London. K Harris, MA, MD, FRCP, consultant nephrologist, University Hospitals of Leicester, John Walls Renal Unit, Leicester General Hospital, Leicester.

\section{Address for correspondence}

Dr Simon de Lusignan, Division of Community Health Sciences, Hunter Wing, St George's - University of London, London SW17 0RE. E-mail: slusigna@sgul.ac.uk

Submitted: 29 August 2009; Editor's response: 3 November 2009; final acceptance: 16 December 2009. (C)British Journal of General Practice

This is the full-length article of an abridged version published in print. Cite this article as: Br J Gen Pract 2010; DOI: $10.3399 /$ bjgp10X502164. 
much of its management can be carried out in primary care, and general practice computer records provide reliable access to data about the quality of management of this condition. ${ }^{9} \mathrm{CKD}$ for the purposes of this review is defined as an estimated glomerular filtration rate (eGFR) of $<60 \mathrm{ml} / \mathrm{min} / 1.73 \mathrm{~m}^{2}$ (that is, stage 3 to 5 CKD). eGFR is derived from four pieces of data: age, sex, serum creatinine, and, where appropriate, corrected for ethnicity. ${ }^{10,11}$ CKD is strongly associated with cardiovascular risk and cardiovascular comorbidities including diabetes. ${ }^{12}$ Progression of CKD may lead to established renal failure requiring renal dialysis or transplantation; people with significant proteinuria are particularly at risk. The mainstay of primary care management is strict control of systolic blood pressure, especially in people with diabetes or proteinuria, and management of cardiovascular risk. ${ }^{1}$ More aggressive management of blood pressure in CKD, especially in people with proteinuria, slows the progression of CKD. ${ }^{13}$ In the UK, national guidance has set out management goals, ${ }^{14,15}$ supported by a financially incentivised chronic disease-management programme in primary care, the Quality and Outcomes Framework (QOF). ${ }^{16}$ These initiatives have raised awareness of the condition; however, a significant gap exists in the quality of primary care management, including the suboptimal control of blood pressure. ${ }^{17,18}$

Two recent systematic reviews of qualityimprovement (Ql) strategies in hypertension have been published. Walsh et al included a wide range of study designs and QI interventions to lower blood pressure; ${ }^{19}$ before and after recording of blood pressure was a precondition for inclusion in their analysis. Of 3000 citations, 44 articles underwent quantitative analysis. A median reduction in systolic blood pressure of $4.5 \mathrm{mmHg}$ was found in intervention groups. QI interventions involving team or organisational change may have the largest effect, although as many of the interventions were complex it was often hard to discern which component was of greatest importance. Fahey et al restricted their analysis to randomised controlled trials (RCTs) in primary care or other community or office settings; ${ }^{20}$ 7000 relevant citations were identified, and 56 trials included in their meta-analysis. The findings were dominated by the large Hypertension Detection and Follow-up (HDFP) programme, which showed a large reduction in systolic blood pressure of $11.7 \mathrm{mmHg},{ }^{21,22}$ but none of the other included studies were associated with large clinically important reductions. However, neither of these reviews included any subgroup analysis in CKD patients, a population in whom blood pressure control is widely recognised to be challenging and frequently requires the use of multiple antihypertensive agents.

\section{How this fits in}

The management of CKD is increasingly a responsibility of primary care.

Achieving blood pressure control is important to reduce the risks of

cardiovascular disease and end-stage renal disease, but is frequently

challenging. A small number of comparative quality improvement studies

suggest that significant reductions in blood pressure can be achieved through

non-doctor led educational and therapeutic interventions.

Prior to embarking on a programme of research to explore how to improve the quality of primary care management of $\mathrm{CKD},{ }^{23}$ a systematic review was carried out to assess the efficacy of QI strategies to lower systolic blood pressure in people with CKD, using systolic blood pressure reduction as a surrogate for reducing cardiovascular risk and slowing the progression of renal disease.

\section{METHOD}

\section{Objectives}

The study objective was to identify the effect of QI interventions upon the primary outcome measures, reduction in systolic blood pressure, or delay or reduction in the onset of established renal failure. Secondary outcome measures included: diastolic blood pressure; change in diastolic blood pressure; percentage of patients achieving systolic or diastolic blood pressure within a target range; and any recording of accelerated decline in eGFR or change in albuminuria or proteinuria. The QI interventions were grouped into: educational interventions; interventions providing audit and comparative feedback; and organisational or team change.

An additional aim was to explore, through subgroup analysis, the influence of the interventions on people with milder (stage 3) or more severe (stage 4 and 5) CKD; the setting of care (outpatients, shared care, community or primary care); the management of patients with and without proteinuria; and the management of comorbidities, especially diabetes.

\section{Literature search}

An appropriate search strategy was developed, in collaboration with the Cochrane Effective Practice and Organisation of Care Group (EPOC) in Canada, ${ }^{24}$ and the Cochrane Renal Group in Australia. ${ }^{25}$ These groups also ran the searches for the study on their own databases, which have both been developed to identify literature from key bibliographic databases. Their databases are complementary: EPOC identifies reviews of interventions designed to improve practice and clinical effectiveness; the Cochrane Renal Group identifies RCTs and other controlled clinical trials (CCTs). These were returned in March 2008, the date of the last search. The search terms used were: (hypertens $^{\star}$ or antihypertens ${ }^{\star}$ or blood pressure or 
systolic BP or CVD or cardiovascular) and (kidney ${ }^{*}$ or renal or nephrol* or CKD or glomerular filtration rate or GFR or eGFR or creatinine). Both Cochrane groups run ongoing searches to identify any trials of QI interventions relevant to primary care and/or renal disease, respectively.

\section{Inclusion and exclusion criteria}

Only studies that had a control or comparator arm were included. The comparator arm might be 'usual practice' or a small-scale intervention such as 'guidelines and prompts'. Acceptable designs included: RCT and cluster RCT; other CCT including studies containing at least two cohorts assembled prospectively using an arbitrary but non-random allocation procedure; and before and after studies (with a contemporaneous observation for cohorts differing in exposure to the $\mathrm{Ql}$ intervention[s]).

Included subjects were adults with hypertension treated and stage 3 to 5 CKD (equivalent to an eGFR $<60 \mathrm{ml} / \mathrm{min} / 1.73 \mathrm{~m}^{2}$ ) managed in an ambulatory care setting: primary care or community setting, shared care, or hospital outpatients. As a substantial proportion of people with diabetes have CKD, diabetes was used as a proxy for CKD where impaired renal function was reported. A previous study of routinely collected data reported that at least $31 \%$ of people with diabetes have CKD. ${ }^{12}$

Studies not meeting the above criteria were excluded; additionally, articles published before 1990; those not on human subjects; and those not in English were not included. Studies of dialysis patients were also excluded. The cut-off of 1990 was selected because there was no guidance on CKD management or evidence base for interventions prior to this time. ${ }^{26}$ There was also concern about the use of angiotensin-converting enzyme inhibitors (which were not the mainstay of management) revealing renal artery stenosis and precipitating renal failure. ${ }^{27}$ Creatinine assays were non-standardised at that time, making comparisons more difficult. ${ }^{28}$

\section{Study assessment}

Titles and abstracts were screened by two independent observers to determine relevance. Disagreements were resolved by consensus. Relevant full abstracts and full texts were screened by two independent observers. Using a structured collection form, data were extracted on: study population; interventions; study design; outcomes; and potential sources of bias.

The studies were assessed in four steps: (1) reviewing the abstracts to identify relevant full papers; (2) extracting data about the quality and characteristics of the studies (type of study, subjects and setting, process of randomisation or type of comparator group, outcome measure); (3) extracting the results (size of study population, outcome measures [blood pressure or progression to established renal failure, change in eGFR, subgroups identified]); and (4) combining results taking into account clinical homogeneity (that is, similarity of populations and settings). A meta-analysis of the results was conducted where appropriate. Where this was not possible, but studies contain relevant information, a narrative review is provided.

\section{Statistical analysis}

Results from randomised controlled trials, quasirandomised trials, and before and after studies were combined. For change in blood pressure, a weighted mean difference with a random effects model and 95\% confidence interval $(\mathrm{Cl})$ was used. Absolute measurements of blood pressure were combined with change measurements if no change measurements could be obtained from the authors of the papers. Dichotomous outcomes (progression to established renal failure, or number or patients achieving target blood pressure) were combined using odds ratios and the Mantel-Haenszel method with random effects. Heterogeneity was measured using the Higgins 12 method, and investigated using the prespecified subgroups.

\section{Sensitivity analysis}

Study quality was used as a criterion for sensitivity analysis. The study planned to compare the outputs of the studies that met the highest quality criteria RCTs - with those studies with lower quality criteria scores, using statistical tests for interaction. The results of using fixed and random effects models were compared, and the study aimed to use funnel plots to look for publication bias.

\section{RESULTS}

\section{Initial review of the search results}

The searches identified 69 studies: 26 from EPOC and 43 from the renal group. The authors independently agreed that, from the abstract, 35 did not fit the inclusion criteria, and then jointly agreed to reject another four studies, leaving 30 studies for which full papers were requested. The main reasons for rejection were: non-relevant patient group (patients with established renal failure treated by dialysis, or patients with urinary or catheter infection; lack of comparator group; or studies focused on another specific area (for example, stroke or renal anaemia). An overview of the process of selection of the core articles is shown in Figure 1.

\section{Review of the full papers}

The study then set out to obtain full versions of the 


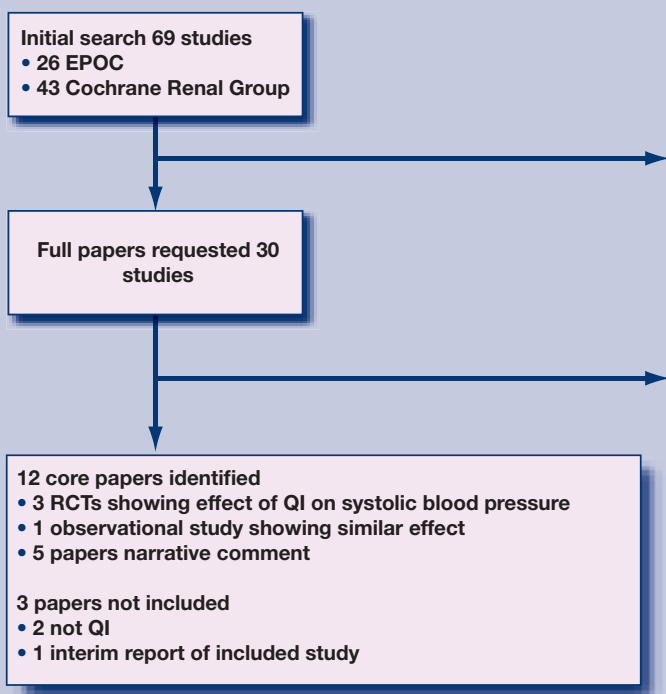

30 selected papers. A spreadsheet was used to independently assess each paper, recording subject and settings, whether randomised, the comparator group, and the outcome measures. The findings were then reviewed. It was not possible to obtain copies of six of these papers from the British Library; 12 papers were identified for final inclusion. The main reasons for exclusion were: pre-1990 study not relevant to current practice $(n=4)$; no comparator group ( $n=3$ ); not a QI intervention $(n=3)$; study based mostly on dialysis patients $(n=2)$; and no blood pressure data $(n=2)$. Two other papers were rejected: one lacked blood pressure data, and the other because of pre-1990 study overlap. For one of the papers, the authors were approached, unsuccessfully, to provide before and after blood pressure and serum creatinine data. ${ }^{29}$

\section{Detailed extraction of the results}

Of the final 12 studies, four could be included in a quantitative comparative analysis of their effect on
Excluded 39 papers

- 22 specialist management of renal patients

dialysis, transplant etc

- 5 urinary or catheter infection

- Others: specific focus e.g. stroke or anaemia

Excluded 18 papers

4 pre-1990

3 no comparator group

3 not QI intervention

2 mainly a study of specialist patients - dialysis and

transplantation

2 no blood pressure data (second reason)

- 5 papers no full text copy available
Figure 1. Selection of core articles. systolic blood pressure; three were randomised studies and one was an observational study with usual practice group as a comparator (Figure 2). Narrative findings are reported from five other studies, and a further two were excluded which, on closer examination, were deemed not to be QI interventions. ${ }^{30,31}$ Finally, another study was excluded because it was the 3-year follow-up of a study, ${ }^{32}$ superseded by a 5-year follow-up, which was included. ${ }^{33}$

Three sets of quantitative results from three RCTs were brought together. All were well-designed studies showing the effects of nurse- or pharmacistled interventions, though with very specific and different patient groups (Table 1). The first is a randomised study of renal transplant patients who were living in the community. ${ }^{34}$ The second study showed the effectiveness of a nurse-led intervention in the management of black men with hypertension. ${ }^{33}$ The third RCT was a Canadian study of a nurse intervention in First Nations people; although a study

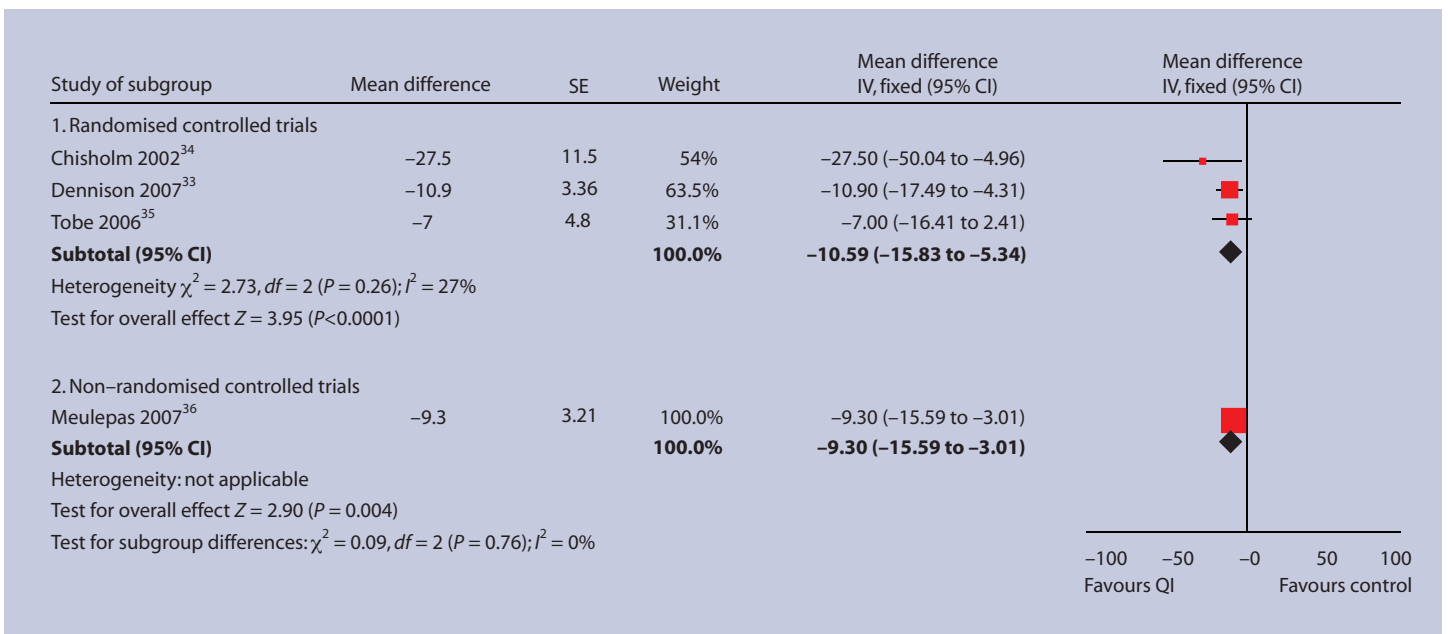

Figure 2. Mean reduction in systolic blood pressure in three randomised and one non-randomised study of quality-improved interventions. 


\section{Table 1. Controlled trials and an observational study of QI interventions to lower systolic blood pressure.}

\begin{tabular}{lllll} 
Brief reference & Sample & Type of study & Intervention & Outcome \\
\hline Randomised studies & & & & \\
\hline Chisholm MA, et al. & $n=13$ intervention; & RCT into receiving a & A clinical pharmacist & Patients in intervention \\
Effect of clinical & $n=10$ control & pharmacy-based intervention & performing medication & group had a mean systolic \\
pharmacy services. & & compared with usual & reviews & blood pressure change at \\
Ethn Dis 2002; 12(3): & post-transplant care & & 12 months of -5 versus \\
392-397. ${ }^{34}$ & & & $+18 \mathrm{mmH}$ in control
\end{tabular}

\section{Dennison CR, et al. $\quad n=157$ more 5-year randomised trial of Nurse-led educational,} Urban AfricanAmerican men. Am J Hypertens 2007;

\section{intensive; $n=153$ more- versus less-intensive less intensive}

behavioural, and intervention. Moreintensive intervention 20(2): 164-171. ${ }^{33}$

pharmacological involved education, individualised multidisciplinary care with nurse practitione visits as needed every 2-3 months, annual home visits, engagement of social support, and adjustment of antihypertensive regime. Less-intensive intervention comprised education and provision of a list of community hypertension care sources

Tobe SW, et al. Nurse- $n=50$ intervention; RCT of two communitydirected hypertension $n=49$ control based strategies for treatment. CMAJ 2006; 174(9): 1267-1271. ${ }^{35}$ controlling hypertension in First Nations people with type 2 diabetes
Home nurse following a hypertension and diabetes protocol compared with usual practice. In the intervention limb, the patient's drug regimen was titrated according to predefined management algorithm, utilising a stepwise approach to lower blood pressure to a target of $<130 / 80 \mathrm{mmHg}$
The mean serum creatinine in the more- and lessintensive groups was 1.27 and $1.29 \mathrm{mg} / \mathrm{dl} ; 36 \%$ and $45 \%$ respectively had microalbuminuria. Data include change in systolic and diastolic blood pressure (annually for 5 years); and proportion with blood pressure $<140 / 90 \mathrm{mmHg}$ (annually for 5 years)

Notes on inclusion

Although transplant patients, they were well in the community and their kidneys were responsive to therapy, as in CKD

Results are likely to indicate slowing progression in CKD: increased proportions remaining free of $50 \%$ rise in creatinine or remaining free of increase in proteinuria during follow-up in intervention limb. Possible difference due to use of angiotensin-converting enzyme inhibitor

The primary outcome measure was difference in systolic blood pressure between the two groups after 12 months. At 12 months versus baseline, systolic blood pressure fell by $24.0 \pm 13.5 \mathrm{mmHg}$ in the intervention group and by $17.0 \pm 18.6 \mathrm{mmHg}$ in the usual practice group. Data on change in diastolic blood pressure and proteinuria are also reported
Non-randomised study

Meulepas MA, et al. $\quad n=353$ intervention Controlled non-randomised Logistis support of diabetes. Fam Pract 2007; 24(1): 20-25. ${ }^{36}$

\section{(51 GPs); $n=129$ control (21 GPs)}

study. The study was based in the Netherlands. The GPs were the primary research subjects

\begin{tabular}{|c|c|c|}
\hline $\begin{array}{l}\text { Introduction of a diabetes } \\
\text { support service (DSS) to } \\
\text { facilitate implementation of } \\
\text { guidelines for management } \\
\text { of type } 2 \text { diabetes in primary } \\
\text { care. The DSS called up } \\
\text { patients for laboratory } \\
\text { testing, foot examination, } \\
\text { fundus photography, and } \\
\text { appointments with dietician } \\
\text { and diabetes nurse. The } \\
\text { DSS did not provide patient } \\
\text { care itself }\end{array}$ & $\begin{array}{l}2 \text { years post introduction of } \\
\text { the DSS, the difference in } \\
\text { the change in systolic blood } \\
\text { pressure (from } 1 \text { year prior } \\
\text { to intervention to } 2 \text { years } \\
\text { post) was }-9.3 \text { (-3.0 to } \\
-15.6) \text { mmHg in intervention } \\
\text { group compared with } \\
\text { control. Data on change in } \\
\text { diastolic blood pressure, } \\
\text { and proportions meeting } \\
\text { blood pressure targets } \\
\text { (150/85 mmHg) are also } \\
\text { reported }\end{array}$ & $\begin{array}{l}\text { No direct measures of } \\
\text { renal function were } \\
\text { available. Study is } \\
\text { included as a high } \\
\text { proportion of individuals } \\
\text { with type } 2 \text { diabetes } \\
\text { will have CKD }\end{array}$ \\
\hline
\end{tabular}

Although severe rena impairment (serum creatinine $>250 \mu \mathrm{mol} / \mathrm{l}$ ) were excluded, mean serum creatinine in the intervention limb was $73 \pm 16 \mu \mathrm{mol} / \mathrm{l}$, and the population had significant proteinuria (albumin/creatinine ratio $25 \pm 72 \mathrm{mg} / \mathrm{mmol}$ 
Table 2. Narrative summary of other studies considered in depth but not contributing quantitative data.

\begin{tabular}{lll} 
Brief reference & Sample & Type of study \\
\hline Binik YM, et al. & $n=87$ intervention; & A randomised study on 204 \\
Live and learn. & $n=92$ standard & patients with advanced CKD \\
J Nerv Ment Dis & education; $n=25$ & (not yet on renal replacement) \\
1993; 181: & 'not part of education' & \\
371-376. & &
\end{tabular}

Intervention

Enhanced or standard

educational package

predominantly nurse

delivered. Education was

directed towards

and involved an individually

\begin{tabular}{lll}
\hline Jaber LA, et al. & $n=17$ intervention; & A randomised controlled study \\
Pharmaceutical & $n=22$ control & in diabetes $(n=532$, \\
care. Ann & & predominantly older black \\
Pharmacother & & females with type 2 diabetes) \\
1996; 30 (3): & &
\end{tabular}

$238-243 .{ }^{38}$ preparation for dialysis,

administered slide presentation and booklet 11.8 months respectively

Patient and physician Improvements in glycated

education by a pharmacist. haemoglobin found. No

Education was provided on improvement in blood

diabetes, medications, diet, pressure or renal function

exercise, glucose monitoring,

and self-adjustment of

hypoglycaemic regimes
Notes on inclusion

Did not include blood

pressure, so could not

be included with the

other quantitative

Canada. Those that received analysis

the enhanced and standard

packages started dialysis

fter $14.9 \pm 12.4$ and $10.3 \pm$

$\pm$

No direct measures of renal function were available, mean creatinine was $88 \mu \mathrm{mol} / \mathrm{l}$. No usable data (baseline and postintervention blood pressure reported but no standard error)

\begin{tabular}{|c|c|c|}
\hline $\begin{array}{l}\text { Mazzuca SA, } \\
\text { et al. Diabetes } \\
\text { education study. } \\
\text { Diabetes Care } \\
\text { 1986; } 9(1) \text { : } \\
1-10 .^{39}\end{array}$ & $\begin{array}{l}n=125,134, \text { and } \\
138 \text { for intervention } \\
\text { groups; } n=135 \\
\text { control }\end{array}$ & $\begin{array}{l}\text { Random allocation into a } \\
\text { factorial design of control, } \\
\text { patient, physician, or patient } \\
\text { and physician intervention } \\
\text { groups. Subjects predominant } \\
\text { black older females with } \\
\text { type } 2 \text { diabetes }\end{array}$ \\
\hline
\end{tabular}

Intensive patient education, Reduction in fasting glucose No direct measures of

which was formalised and and glycated haemoglobin renal function were didactic, providing a systematic programme of y diabetes education and delivered by a specialist multidisciplinary team; physician education from an expert; or both

McGhee SM, $\quad n=277$ outpatient Randomised controlled et al. Coordinating care; $n=277$ shared trial and standardizing care; $n=277$ nurse long-term care. practitioner care

Compares different types of care: either standard outpatient care or shared general practice-hospital care, whereby a hospitalbased database generates an annual record on each enrolled patient for the GP and a patient-held record for the patient, including a prompt to attend for a review with the GP; overall responsibility for the patient's care lies with the GP, and the outcomes of the review are returned to the registry so further specialist recommendations can be made where appropriate

New JP, et al. $\quad n=6544$ patients Observational study Measuring clinical with diabetes Before and after effect of introducing an information system available, mean creatinine $88 \mu \mathrm{mol} / \mathrm{l}$. No usable data (baseline and post-intervention blood pressure reported but no standard error)

Process measures of review Did not include blood and wish to continue with care offered pressure results or other indication that patients had CKD

\section{All categories of}

monitoring improved
Comparison of noncontemporaneous groups makes linking cause and effect difficult
$>3.5 \mathrm{mg} / \mathrm{mmol}$ in women is indicative of renal damage and is therefore diagnostic of CKD..$^{15}$ These studies suggest that these QI interventions lower systolic blood pressure by a mean of $10.6 \mathrm{mmHg}$ (95\% confidence interval $[\mathrm{Cl}]=-15.8$ to -5.3 ), and that this effect is statistically significant $(P<0.0001$, Figure 2). Results were very similar with the use of a random effects model (mean difference $-10.90 \mathrm{mmHg}$; $95 \% \mathrm{Cl}=-17.72$ to -4.08 ).

The study also included quantitative results from an observational non-randomised study from the Netherlands, as it was felt that the improved blood pressure control achieved in this non-randomised study of diabetes care might well be transferable to 
people with $\mathrm{CKD} ;{ }^{36}$ this reduction is of the same order - a reduction in systolic blood pressure of $8.3 \mathrm{mmHg}(95 \% \mathrm{Cl}=-15.6$ to $-3.0 ; P=0.004)$.

Narrative observations have been made about the remaining five papers (Table 2). The first group of three papers showed improvements in systolic blood pressure as a result of educational interventions by a range of clinical staff: nurse-provided intensive educational interventions in people with declining kidney function in a pre-dialysis setting; ${ }^{37}$ the effectiveness of a pharmaceutical care model where all diabetes care management was provided by a pharmacist; ${ }^{38}$ and the effect of highly formalised diabetes education. ${ }^{39}$ The remaining two focused on different models for the delivery of care. ${ }^{30,31}$ The first compared different models for ambulatory care in hypertension, but reported on the process rather than any effects on blood pressure in people with likely CKD. ${ }^{29}$ The final paper showed how an information system contributed to QI but made noncontemporaneous comparison of groups. ${ }^{40}$

\section{DISCUSSION}

\section{Summary of main findings}

There are few studies that report the effects of $Q$ I interventions in primary care for people with CKD. The small number of trials carried out in this domain were often conducted on high-risk populations including ethnic minorities, although their pooled effects appear similar. They appear to have a positive effect of lowering systolic blood pressure by around $10 \mathrm{mmHg}$.

\section{Strengths and limitations of the study}

This systematic review is the first summarising the effects of quality improvement interventions on blood pressure control in people with CKD. Although only three randomised studies were available for quantitative comparative analysis, these studies all examined interventions delivered by non-doctor healthcare professionals, and a positive effect was seen in all. The magnitude of this effect was similar to that in the observational non-randomised study also included in the quantitative analysis.

The search was limited to that provided through the Cochrane review groups, which is a potential source of bias; however, this approach may have led to more systematic inclusion of articles than if the study had run its own searches. It is also accepted that only searching for English language papers introduces language bias, but no facilities were available to translate papers. The study conclusions are limited by the small number of studies identified, and it was not possible to complete a meaningful sensitivity analysis based on study quality, as intended in the method.

It is also recognised that some case studies were included on the basis of a high likelihood of CKD rather than on the basis of eGFR readings.

\section{Comparison with existing literature}

Nurse interventions have been carried out in CKD to improve quality, but in an observational study with no comparator group rather than in any form of trial. ${ }^{41}$ However, the reduction achieved in systolic blood pressure $(9 \mathrm{mmHg})$ is similar to that achieved in the QI studies reviewed earlier in this paper.

\section{Implications for future research and clinical practice}

It appears that educational interventions run by nurses and pharmacists can be effective in lowering blood pressure in high-risk groups - although this may or may not be generalisable across the wider population. Practitioners with lists that have high rates of diabetes and vascular disease could consider implementing targeted services that actively call in and follow-up people at increased cardiovascular risk or who have diabetes. These patients should have their eGFR checked and their urine screened for proteinuria using a quantitative measure of proteinuria - ideally the albumin/creatinine ratio. Those with positive tests should have their blood pressure and cardiovascular risk controlled in line with national guidance. ${ }^{15}$

The gap identified in the literature justifies the QI intervention trial planned, ${ }^{23}$ but also suggests that there is additional scope to test targeted, possibly non-doctor-led, educational and therapeuticfocused interventions with higher-risk patients.

There is a place for QI in CKD. That place appears to be demonstrated for specialist team members dealing with selected high-risk populations. Further research is needed to establish the place of other broader cross-practice and locality- and technologybased QI initiatives.

\section{Funding body}

This study is funded as part of two awards by open competition and subject to peer review: $:^{23}$ from the Health Foundation award to investigate QI in CKD; and from an Edith Murphy Foundation award to investigate QI in diabetes in CKD.

\section{Competing interests}

Simon de Lusignan was the GP expert adviser for the Quality and Outcomes Framework (QOF CKD) Indicator. SdeL has received funding for research staff from Roche for the data analysis which formed part of the NEOERICA study (references 2, 5, 6, and 8 are papers arising from this study). He has received sponsorship from Pfizer to speak at two cardiovascular meetings. Hugh Gallagher is a panel member and expert advisor for the QOF. He has received funding from several pharmaceutical companies for educational presentations on CKD, and an honorarium from a GP magazine to write an article on CKD (joint with Simon de Lusignan). Kevin Harris has current research grants from the Edith Murphy Foundation (Quality Improvement in CKD due to diabetes - £450 000) and the National Institute for Health Research (CLAHRC 2008-2014: Prevention of 
Chronic Disease and its Associated Co-Morbidity theme $\sim £ 4$ million out of $\sim £ 20$ million total). In the last 5 years he has also received funding (travel support and ad hoc honararia) from: Roche, Ortho Biotech, Amgen, Baxter, and Boehringher. He is a member of Advisory Boards of Roche, Genzyme, Shire, Baxter, and Novartis. Christopher Cates has no competing interests.

\section{Discuss this article}

Contribute and read comments about this article on the Discussion Forum: http://www.rcgp.org.uk/bjgp-discuss

\section{REFERENCES}

1. Gomez GB, de Lusignan S, Gallagher H. Chronic kidney disease: a new priority for primary care. Br J Gen Pract 2006; 56(533): 908-910.

2. Klebe B, Farmer C, Cooley R, et al. Kidney disease management in UK primary care: guidelines, incentives and information technology. Fam Pract 2007; 24(4): 330-335.

3. Glynn LG, Buckley B, Reddan D, et al. Multimorbidity and risk among patients with established cardiovascular disease: a cohort study. Br J Gen Pract 2008; 58(552): 488-494.

4. Farrington K, Udayaraj U, Glig J, Feehally J. ESRD incident rates in 2007 in the UK: national and centre-specific analyses In: Renal Registry Report 2008. Bristol: Renal Registry, 2008: 13-41.

http://www.renalreg.com/Report-Area/Report\%202008/Chapter03.pdf (accessed 6 Jan 2010).

5. John R, Webb M, Young A, Stevens PE. Unreferred chronic kidney disease: a longitudinal study. Am J Kidney Dis 2004; 43(5): 825-835.

6. Klebe B, Irving J, Stevens PE, et al. The cost of implementing UK guidelines for the management of chronic kidney disease. Nephrol Dial Transplant 2007; 22(9): 2504-2512.

7. De Lusignan S, Chan T, Stevens P, et al. Identifying patients with chronic kidney disease from general practice computer records. Fam Pract 2005; 22(3): 234-241.

8. Coresh J, Astor BC, Greene T, et al. Prevalence of chronic kidney disease and decreased kidney function in the adult US population: Third National Health and Nutrition Examination Survey. Am J Kidney Dis 2003; 41(1): 1-12.

9. Anandarajah S, Tai T, de Lusignan S, et al. The validity of searching routinely collected general practice computer data to identify patient with chronic kidney disease (CKD): a manual review of 500 medical records. Nephrol Dial Transplant 2005; 20(10): 2089-2096.

10. Coresh J, Stevens LA. Kidney function estimating equations: where do we stand? Curr Opin Nephrol Hypertens 2006; 15(3): 276-284.

11. Lamb EJ, Tomson CR, Roderick PJ. Clinical Sciences Reviews Committee of the Association for Clinical Biochemistry. Estimating kidney function in adults using formulae. Ann Clin Biochem 2005; 42(5): 321-345.

12. New JP, Middleton RJ, Klebe B, et al. Assessing the prevalence, monitoring and management of chronic kidney disease in patients with diabetes compared with those without diabetes in general practice. Diabet Med 2007; 24(4): 364-369.

13. Jones C, Roderick P, Harris S, Rogerson M. An evaluation of a shared primary and secondary care nephrology service for managing patients with moderate to advanced CKD. Am J Kidney Dis 2006; 47(1): 103-114.

14. Department of Health. National service framework for renal services part two: chronic kidney disease, acute renal failure and end of life care. London: Department of Health, 2005. http://www.dh.gov.uk/en/Publicationsandstatistics/Publications/Publica tionsPolicyAndGuidance/DH_4101902 (accessed 26 Jan 2010).

15. National Institute for Health and Clinical Excellence (NICE). Early identification and management of chronic kidney disease in adults in primary and secondary care. Clinical guideline CG73. London: NICE 2008. http://guidance.nice.org.uk/CG73 (accessed 6 Jan 2010).

16. NHS Primary Care Commissioning. Quality and Outcomes Framework. http://www.pcc.nhs.uk/qofhome (accessed 6 Jan 2010).

17. Stevens PE, O’Donoghue DJ, de Lusignan S, et al. Chronic kidney disease management in the United Kingdom: NEOERICA project results. Kidney Int 2007; 72(1): 92-99.

18. De Lusignan $\mathrm{S}$, Chan $\mathrm{T}$, Gallagher $\mathrm{H}$, et al. Chronic kidney disease management in southeast England: a preliminary cross-sectional report from the QICKD - Quality improvement in chronic kidney disease study. Prim Care Cardiol J 2009; 12(1): 33-9. http://www.pccj.eu/pdf/3323/Vol2_Num1_April-MayJune_2009_p33-39.pdf?sid=5501246170832c38 (accessed 6 Jan 2010).
19. Walsh JM, McDonald KM, Shojania KG, et al. Quality improvement strategies for hypertension management: a systematic review. Med Care 2006; 44(7): 646-657.

20. Fahey T, Schroeder K, Ebrahim S. Educational and organisational interventions used to improve the management of hypertension in primary care: a systematic review. Br J Gen Pract 2005; 55(520): 875-882.

21. No authors listed. Five-year findings of the hypertension detection and follow-up program. II. Mortality by race-sex and age. Hypertension Detection and Follow-up Program Cooperative Group. JAMA 1979; 242(23): 2572-2577.

22. No authors listed. Persistence of reduction in blood pressure and mortality of participants in the Hypertension Detection and Follow-up Program. Hypertension Detection and Follow-up Program Cooperative Group. JAMA 988; 259(14): 2113-2122.

23. De Lusignan $\mathrm{S}$, Gallagher $\mathrm{H}$, Chan T, et al. The QICKD study protocol: a cluster randomised trial to compare quality improvement interventions to lower systolic BP in chronic kidney disease (CKD) in primary care. Implement Sci 2009; 4: 39.

24. The Cochrane Effective Practice and Organisation of Care Group (EPOC). http://www.epoc.cochrane.org/ (accessed 6 Jan 2010).

25. The Cochrane Renal Group. http://www.cochrane-renal.org/ (accessed 6 Jan 2010).

26. Go AS, Chertow GM, Fan D, et al. Chronic kidney disease and the risks of death, cardiovascular events, and hospitalization. N Engl J Med 2004; 351(13): 1296-1305.

27. Kalra PA, Mamtora H, Holmes AM, Waldek S. Renovascular disease and renal complications of angiotensin-converting enzyme inhibitor therapy. Q J Med 1990; 77(282): 1013-1018.

28. Landis JR, Gaughan C, Joffe M. Inter-laboratory serum creatinine ( $\mathrm{sCr}$ ) calibration study. J Am Soc Nephrol 2003; 14: 294A-294A.

29. McGhee SM, McInnes GT, Hedley AJ, et al. Coordinating and standardizing long-term care: evaluation of the west of Scotland sharedcare scheme for hypertension. Br J Gen Pract 1994; 44(387): 441-445.

30. De Berardis G, Pellegrini F, Franciosi M, et al. QuED Study. Quality of care and outcomes in type 2 diabetic patients: a comparison between general practice and diabetes clinics. Diabetes Care 2004; 27(2): 398-406.

31. So WY, Tong PC, Ko GT, et al. Effects of protocol-driven care versu usual outpatient clinic care on survival rates in patients with type 2 diabetes. Am J Manag Care 2003; 9(9): 606-615.

32. Hill MN, Han HR, Dennison CR, et al. Hypertension care and control in underserved urban African American men: behavioral and physiologic outcomes at 36 months. Am J Hypertens 2003; 16(11 Pt 1): 906-913.

33. Dennison CR, Post WS, Kim MT, et al. Underserved urban African American men: hypertension trial outcomes and mortality during 5 years. Am J Hypertens 2007; 20(2): 164-171.

34. Chisholm MA, Mulloy LL, Jagadeesan M, et al. Effect of clinical pharmacy services on the blood pressure of African-American renal transplant patients. Ethn Dis 2002; 12(3): 392-397.

35. Tobe SW, Pylypchuk G, Wentworth J, et al. Effect of nurse-directed hypertension treatment among First Nations people with existing hypertension and diabetes mellitus: the Diabetes Risk Evaluation and Microalbuminuria (DREAM 3) randomized controlled trial. CMAJ 2006; 174(9): 1267-1271.

36. Meulepas MA, Braspenning JC, de Grauw WJ, et al. Logistic support service improves processes and outcomes of diabetes care in general practice. Fam Pract 2007; 24(1): 20-25.

37. Binik YM, Devins GM, Barre PE, et al. Live and learn: patient education delays the need to initiate renal replacement therapy in end-stage renal disease. J Nerv Ment Dis 1993; 181: 371-376.

38. Jaber LA, Halapy H, Fernet M, et al. Evaluation of a pharmaceutical care model on diabetes management. Ann Pharmacother 1996; 30(3): 238-243.

39. Mazzuca SA, Moorman NH, Wheeler ML, et al. The diabetes education study: a controlled trial of the effects of diabetes patient education. Diabetes Care 1986; 9(1): 1-10.

40. New JP, Hollis S, Campbell F, et al. Measuring clinical performance and outcomes from diabetes information systems: an observational study. Diabetologia 2000; 43(7): 836-843.

41. Richards N, Harris K, Whitfield M, et al. Primary care-based disease management of chronic kidney disease (CKD), based on estimated glomerular filtration rate (eGFR) reporting, improves patient outcomes. Nephrol Dial Transplant 2008; 23(2): 549-555. 